\title{
Correction to: Effects of Initial Austenite Grain Size on Microstructure and Mechanical Properties of 5\% Nickel Cryogenic Steel
}

\author{
Published online: 29 May 2019 \\ (c) ASM International 2019

\section{Correction to: \\ Metallography, Microstructure, and Analysis (2019) 8:241-248 \\ https://doi.org/10.1007/s13632-019-00523-6}

Tao Xiong ${ }^{1}$. Guang $X_{u^{1}}$. Qing Yuan ${ }^{1} \cdot$ Hai-jiang Hu $\mathbf{u}^{1}$. Jun-yu Tian ${ }^{1}$

The authors have indicated that they mistakenly provided the wrong TEM micrograph for Fig. 8 of their paper. The authors have provided the correct TEM micrograph, which is shown below (Fig. 8).

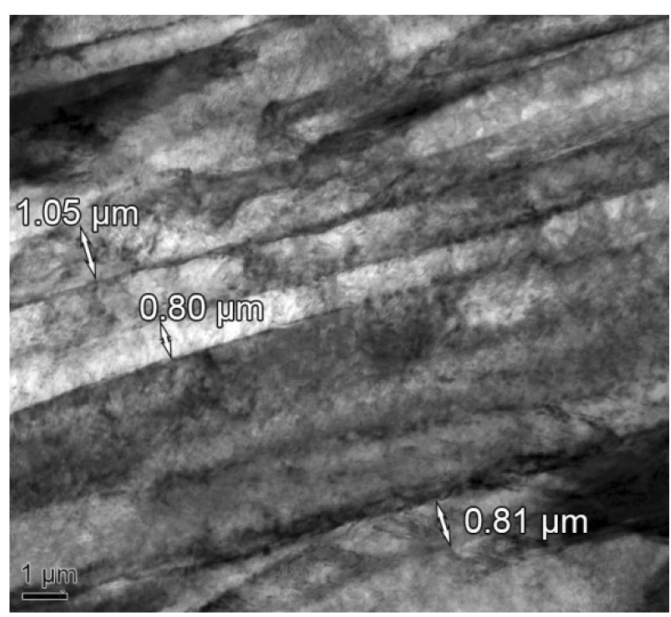

Fig. 8 Coarsening TM in the specimen austenitized at $830{ }^{\circ} \mathrm{C}$ for

$100 \mathrm{~min}$

Publisher's Note Springer Nature remains neutral with regard to jurisdictional claims in published maps and institutional affiliations
The original article can be found online at https://doi.org/10.1007/ s13632-019-00523-6.

Guang Xu

xuguang@wust.edu.cn

Tao Xiong

taoxiong@163.com

Qing Yuan

yuanqing@wust.edu.cn

Hai-jiang $\mathrm{Hu}$

huhaijiang@wust.edu.cn

Jun-yu Tian

tianjunyu@wust.edu.cn

1 The State Key Laboratory of Refractories and Metallurgy, Hubei Collaborative Innovation Center for Advanced Steels, Wuhan University of Science and Technology, 947 Heping Avenue, Qingshan District, Wuhan 430081, China 